\title{
Plural Leadership During Organisational Transformation Initiatives (Vertical \& Horizontal)
}

\author{
Nawaf AlGhanem¹, Ashley Braganza1, and Tillal Eldabi ${ }^{1,2}$ \\ ${ }^{1}$ College of Business, Arts and Social Sciences, Brunel University London, UK \\ ${ }^{2}$ College of Business \& Finance, Ahlia University, Bahrain
}

\section{Abstract}

Organizational transformation and change scholars and researchers published many articles linking and studying the effect of vertical (transactional) leadership and horizontal (transformational) leadership on organizations during transformation. As much attention has been given in the last two decades to transformational leadership as being one of the trendiest leadership styles that focuses on the relation between followers and leaders to achieve better performance during organizational transformation, transactional leadership is still of benefit. This paper bridges organizational

Corresponding Author:

Nawaf AIGhanem

Nawaf.Alghanem@brunel.ac.uk

Received: 22 July 2019

Accepted: 16 September 2019

Published: 19 September 2019

Publishing services provided by

Knowledge E

(c) Nawaf AlGhanem et al. This article is distributed under the terms of the Creative Commons

Attribution License, which

permits unrestricted use and redistribution provided that the original author and source are credited.

Selection and Peer-review under the responsibility of the PwR Symposium Conference Committee.

\section{G OPEN ACCESS}

transformation and leadership literature and show the importance of transformational (horizontal) leadership alongside transactional (vertical) leadership in achieving efficient performance and optimal results during organizational transformation.

Methodology: A literature review will be conducted based on literature related to certain key word and through a systematic literature review protocol.

Keywords: Organizational transformation, leadership, transactional leadership, transformational leadership.

\section{Introduction}

Leadership is a challenge in global economy where business environment is dynamic and competitive. Coping with such competitive economic environment requires organisations to transform and go through organizational changes to be able to keep up with business trends. Global markets and geopolitics environment fervently evoke organizations, whether large or small to apply changes and modify the way they do businesses, or even change their organizational cultures and beliefs. In the current business environment an essential contingent upon how organization can manage to cope with change, especially changes that are generated from strategic decisions (Levene and Braganza, 1996). Organizational change is a necessity for organizations to survive and prosper. Most organizations compete by changing continuously(Brown \& Eisenhardt, 1997; Weick \& Quinn 1999). One approach leader can take to create a 
competitive advantage is to cultivate an organizational climate which promotes change. Organizations that are vigorous at making incremental as well as radical changes are better positioned to survive tough environment (Henderson \& Clark, 1990).

Organisational transformation is a whole process which depends on the efficiency and success of such changes which depends on the way those changes are executed and introduced to organizations population. Propper organisational changes execution are dependent on how good and effective leadership is. Leaders and followers are key elements to efficient implantation of change (Kempster et al., 2014; White et al., 2016). As the leadership subject is an area of interest many scholars and researchers, many theories and researches has been published and many leadership styles has evolved. These theories and leadership styles will be discussed in this paper.

This paper will highlight the importance of transactional leadership as an important and significant aspects of change management that results in achieving continuous performance and relationship improvements during organisational change alongside transformational leadership with more focus on middle and lower management and employees as previous studies show results of transformation leadership on Quality and employee performance during organisational transformation. The objective of this research is exploring the need for traditional transactional leadership and charasmatic transformational leadership and its impact on achieving results during organisational transformation. This study will also explore the need of implementing social network leadership approach to improve performance and ensure collective changes when organizations are going through its transformation phase.

This paper is organised in the following sequence. First, we will be reviewing literature related to organisational transformation, leadership theory in a chronological sequence to see how leadership theory literature developed overtime. The paper focuses on the relation between organizational transformation and leadership theory. Then, we will discuss the importance of plural leadership during organisational transformation. Finally, the paper will be concluded with potential areas for future research.

\section{Research Background}

Organisational transformation is a process where leadership style and leaders are the means of implementing those changes efficiently, continuously, consistently and accurately. The dilemma of which leaders and which leadership styles should be used as a mean of implementing those changes still exists. Many studies, researches and scholars had arguments in defending different leadership styles (Brown \& Eisenhardt, 
1997; Weick \& Quinn 1999; Feldman \& Pentland, 2003). Those arguments create connections between different Schools of thoughts as some still believe in old school methods of leadership while others believe in new trendy leadership styles. As many researchers highlighted the importance of having transformation leadership to mitigate tension and facilitate the efficient performance of employees (Bass \& Riggio, 2006; Pawar \& Eastman, 1997). Transformational leadership is often linked with managerial effectiveness during the organisational change. Transformation leaders recognise the need for change. Transactional leadership on the other hand reflects as leader of appetite towards identification of followers needs and aspiration (Jung, 2001; Paracha et al., 2012). The transactional leadership style developed by Bass is based on the hypothesis that followers are motivated through a system of rewards and punishment. Transactional leadership is associated with strong organizational cultures that are directive, top-down and evolves around the power and position of those leaders.

Unlike conventional leadership approaches, horizontal transformational leadership requires executive's engagement, empowerment and facilitating to connect and interconnect disparate organisational elements. Having said that proper implementation of changes has to be executed throw different and various leadership styles and schools (Denis et al., 2001; Schneider, 2002). Making the best of these leadership styles and theories should have positive impact, boost performance, and implementation of the desired continuous changes imposed by stakeholders and board members. The research problem is to argue if transactional leadership alongside transformational leadership would add more enhancement towards maximizing the implementation of organizational transformation.

\section{Literature Review}

\subsection{Organizational transformation}

Organizational transformation is an organizational change that goes beyond a mere change in systems to a process that deeply penetrates different organizational layers in order to achieve utmost satisfaction and positive perception of the organization's aspired goals and objectives. One of the definitions of organizational transformation is a term which refers broadly to such activities as re-engineering, redesigning and refining operational systems or a change in the manner the business is carried out in the event of the re-engineering or the restructuring activity. Some studies of corporate transformation hold the opinion that growing, incremental additional capabilities need 
to be further consolidated progressively by firms in order to transform or "rejuvenate" themselves (Francis, Bessant and Hobday, 2003). Furthermore, organizational change is often termed as either incremental or radical (Barezak et al., 2012). Morris and Brandon assert that organizations should position their re-engineering (redesign) projects alongside other change initiatives and schemes taking place including total quality, redesign and empowerment. Additionally, Hammer 1990 holds the opinion that organizations which have made incremental changes, can usually improve what was done earlier by changing a single variable, within the functional structure. In today's economy competitive organizations are those who adapt to markets changing environment and global economy and are able to transform themselves by allowing deep organisational layer changes. It's clear that the main pillar and foundation of the organizations is its ability to satisfy its needs (French and Bell, 2006). However, transformation is observed as an all-pervading, universal, and multifaceted process within a specific business frame and presents vast and immense challenges to any system (Beckhard, 2006). The challenge of organizational transformation in complicated business patterns would primarily require profound depth and insight of theoretical examination, such as exploring possible combinations of individual and plural outlooks of leadership at the pinnacle of the organization (Denis et al, 2012). Yet the literature continues to focus largely on the individual who leads the transformation, rather than on the plurality of individuals and their interactions (Kempster et al., 2014; White et al., 2016). Transformation is a facilitation of radical shift in the organization values, culture, structure, routine and how business is done (Bartunek and Louis, 1988).

As discussed above this paper look at organizational transformation as the mean for organizations both private and public to enhance not only their productivity but run on more efficient performance and internal satisfaction of individuals. The importance of organizational change and transformation emerges from the need to cope and elevate the way business is done throw those changes. With organizational change raises the importance of having a combination of leadership styles and approaches to lead the organization towards achieving those changes. Organizational transformation can take many different forms from radical to incremental to continuous(morphing). Each form of transformation might require different combination of leadership styles.

\subsection{Leadership Theory}

There are many various defining terms of leadership and numerous scholars who have endeavoured to outline the leadership concept (Bass, 1981) which we see in Table 1 
below. The meaning of leadership isn't simply about an individual or a group of individuals at the peak of the hierarchy and chain of command in an organization. Leadership is a process, act or endeavour to exert influence on followers and juniors. Leadership is principally an interpersonal influence, performed in a certain situation, and directed through the communication process toward the achievement of a certain goal or goals (Weschler and Massarik, 2013). It's a social process in which one individual exercise influence on the behaviour of others without the use of warning or violence (Buchanan \& Huczynski, 2010) and the process of influencing the activities of an organized group in its efforts toward achieving a certain goal (Stogdill, 1950). Generally speaking, leadership is the influencing process of leaders and followers to achieve organizational objectives through certain changes (Lussier \& Achua, 2004). It's the incremental influence that a person has beyond his or her formal authority (Vecchio, 1988). Leadership is a process where one individual sets a purpose or a direction for one or a group of induvial and get them to move alongside each other in that direction with competence and commitment (Jaques E. \& Clement, 1994). An influential and visionary leader makes his followers and team members self-convinced that changes and transformation of the organization is vital and essential to the survival and growth in challenging, highly competitive and volatile environments. Since 1980s, the literature on organizational change leadership has been largely influenced by performance models advising on where leadership can be found and how it can lead to change (Bass, 1985; Kotter, 1988; Kuipers et al., 2014).

TABLE 1: Leadership definitions.

\begin{tabular}{|c|c|}
\hline Reference & Leadership definition \\
\hline Follet (1925) & $\begin{array}{l}\text { "It is possible to develop the conception of power-with, a jointly developed } \\
\text { power, a coactive, not a coercive power" }\end{array}$ \\
\hline Pigors (1935) & $\begin{array}{l}\text { "Leadership is a process of mutual stimulation which, by the successful } \\
\text { interplay of individual differences, controls human energy in the pursuit of a } \\
\text { common cause" }\end{array}$ \\
\hline Stoghdill (1950) & $\begin{array}{l}\text { "Leadership may be considered as the process(act) of influencing the activities } \\
\text { of an organised group in its efforts toward goal setting and goal achievement" }\end{array}$ \\
\hline Gibb (1954) & "Leadership is probably best conceived as a group quality" \\
\hline $\begin{array}{l}\text { Hemphill \& Coons } \\
\text { (1957) }\end{array}$ & $\begin{array}{l}\text { "Leadership is the behaviour of an individual when he is directing the activities } \\
\text { of a group toward a shared goal" }\end{array}$ \\
\hline $\begin{array}{l}\text { French \& Raven } \\
\text { (1959) }\end{array}$ & $\begin{array}{l}\text { "Our theory of social influence and power is limited to influence on the person, } \\
\text { P, produced by a social agent, O, where O can be either another person, a role, } \\
\text { a norm, a group or part of a group" }\end{array}$ \\
\hline Prentice (1961) & $\begin{array}{l}\text { "Leadership is the accomplishment of a goal through the direction of human } \\
\text { assistant. A leader is one who successfully marshals his human collaborators } \\
\text { to achieve particular ends" }\end{array}$ \\
\hline $\begin{array}{l}\text { Dansereau et al. } \\
\text { (1975) }\end{array}$ & $\begin{array}{l}\text { "The vertical dyad is the appropriate unit of analysis for examining leadership } \\
\text { processes" }\end{array}$ \\
\hline Hollander (1978) & $\begin{array}{l}\text { "Leadership is a process of influence between a leader and those who are } \\
\text { followers" }\end{array}$ \\
\hline
\end{tabular}




\begin{tabular}{|c|c|}
\hline Reference & Leadership definition \\
\hline Burns (1978) & "Surely its time that....the roles of leader and follower be united" \\
\hline Vecchio (1988) & $\begin{array}{l}\text { "Leadership is the incremental influence that a person has beyond his or her } \\
\text { formal authority" }\end{array}$ \\
\hline Frenandez (1991) & $\begin{array}{l}\text { "We argue that leadership, particularly that aspect of leadership which is } \\
\text { reflected in respect, is inherent in the relations among individuals, not in the } \\
\text { individuals themselves" }\end{array}$ \\
\hline Schein (1992) & $\begin{array}{l}\text { "Leadership is the ability to step outside the culture to start evolutionary } \\
\text { change processes that are more adaptive" }\end{array}$ \\
\hline Meindl (1995) & $\begin{array}{l}\text { "The romance of leadership notion emphasizes followers and their contexts for } \\
\text { defining leadership itself and for understanding its significance" }\end{array}$ \\
\hline House et al. (1999) & $\begin{array}{l}\text { "Leadership is the ability of an individual to influence, motivate, and enable } \\
\text { others to contribute toward the effectiveness and successes of the } \\
\text { organisation" }\end{array}$ \\
\hline Hogg (2001) & $\begin{array}{l}\text { "Leaders may emerge, maintain their position, be effective, and so forth, as a } \\
\text { result of basic cognitive processes" }\end{array}$ \\
\hline $\begin{array}{l}\text { Pearce \& Conger } \\
(2003)\end{array}$ & $\begin{array}{l}\text { "Leadership is broadly distributed among a set of individuals instead of } \\
\text { centralized in hands of a single individual who acts in the role of superior" }\end{array}$ \\
\hline $\begin{array}{l}\text { Howell \& Shamir } \\
(2005)\end{array}$ & $\begin{array}{l}\text { "Followers' self-concepts play a crucial role in determining the type of } \\
\text { relationship they develop with the leader" }\end{array}$ \\
\hline $\begin{array}{l}\text { Balkundi \& Kilduff } \\
\text { (2006) }\end{array}$ & $\begin{array}{l}\text { "Our network approach locates leadership not in attributes of individuals but in } \\
\text { the relationships connecting individuals" }\end{array}$ \\
\hline Lo (2008) & $\begin{array}{l}\text { "Leadership is a communication process of maximizing people potential and } \\
\text { influencing people to achieve a shared goal, in a given situation" }\end{array}$ \\
\hline $\begin{array}{l}\text { Friedrich et al. } \\
\text { (2009) }\end{array}$ & $\begin{array}{l}\text { "Multi individual within the team may serve as leaders in both formal and } \\
\text { informal capacities" }\end{array}$ \\
\hline Yukul (2010) & $\begin{array}{l}\text { "Leadership is the process of influencing others to understand and agree } \\
\text { about what needs to be done and how to do it, and the process of facilitating } \\
\text { individual and collective efforts to accomplish shared objectives" }\end{array}$ \\
\hline DeRue (2011) & $\begin{array}{l}\text { "Leadership is a social interaction process where individuals engage in } \\
\text { repeated leading-following interactions, and through these interactions, } \\
\text { co-construct identities and relationships as leaders and followers" }\end{array}$ \\
\hline Eberly et al. (2013) & $\begin{array}{l}\text { "We posit that what gives rise to the phenomenon of leadership is a series of } \\
\text { often simultaneous events cycles between multiple loci of leadership" }\end{array}$ \\
\hline Yammarino (2013) & $\begin{array}{l}\text { "Leadership is a multi-level.. leader-follower interaction process that occurs in a } \\
\text { particular situation(context)where leader and followers share a purpose and } \\
\text { jointly accomplish things willingly" }\end{array}$ \\
\hline Lord \& Dinh (2014) & $\begin{array}{l}\text { "Leadership is a social process that involves iterative exchange processes } \\
\text { among two or more individuals" }\end{array}$ \\
\hline
\end{tabular}

One of the most defining challenges for leaders is carrying out planned organizational changes that broadly correspond to premeditated interventions intended to modify organizational functioning towards more favourable results (Lipps, Watson \& Westly, 1958). A large number of leadership studies which tackle the relationship between leadership and change do not, however account for the complexity of intra-organizational processes (Yukl, 1999), including the complexity of the organizational change implementation process, which involves a wide spectrum of activities. The planned organizational 
change implementation involves different activities in which leadership competencies might play different roles and has therefore been ignored by leadership literature (Higgs \& Rowland, 2005). This research argues that leadership competency is essential and vital in achieving the planned organizational changes that has been imposed by stakeholders or board of directors. The complexity of leadership required competent and visionary leaders to lead the organization towards the efficient implementation of those planned changes (Lipps, Watson \& Westly, 1958). The organizational transformation literature highlights the complexity of change process as well as leader's role in various transformation implementation activities. The common assumption of most of these studies is that change agents are competent and has the required skills and abilities to play their roles in various change implementation activities.

Nevertheless, leadership is termed by scholars and researchers to traditional and newer leadership theories. Leadership theories traced back from the early twentieth century to the late 70's is referred to as traditional leadership theories, which largely emerged and developed from the 80's to early twenty first century where identified as newer leadership theories (Avolio et at., 2009). At the beginning of this century more team, collective and network focused leadership started evolving and developing alongside the new evolutionary global leadership theory which emerged recently. We will focus on newer leadership theories. Leaders' characteristics can result in better execution of the transformation initiatives taken by the organization (Higgs and Rowland, 2011). Many of leadership theories that have emerged and evolved during the last century has been modified and refined to meet the changing volatility of the business environment. We will be briefly discussing in the next section of this research traditional, newer, team/collective and global leadership theories. This research will principally concentrate on the significance of horizontal and vertical leadership in underlining organizational leadership during organizational transformation.

\subsubsection{Traditional leadership theory}

Traditional leadership theories include: trait-based theories, behaviour theories, situational/contingency leadership theory and leader follower model theory.

\section{Trait based leadership theories}

Great man leadership theory was the first leadership model to evolve in the beginning of the nineteenth century stating that "leadership qualities were inherited" (Hernandez 
et al., 2011, p. 1169). Great-man leadership soon transformed to what was known later as trait leadership theory or a heroic leadership theory that is based on the characteristics of the leader and his ability to motivate the patterns of follower's behaviours by positive influence. Trait-based theories is based on the belief that " certain personality characteristics distinguish leaders from non-leaders" (Hernandez et al., 2011, p.1169). Trait-based leadership has been extended to include neo-trait approach emphasizing " the need to understand the psychological mechanisms through which traits translate into leadership effectiveness" (Hernandez et al., 2011). In this approach raises the argument that " trait alone is not sufficient for business leadership they are only a precondition" (Kirkpatrick and Locke, 1991, p.49). Trait- based theories became famous in the $19^{\text {th }}$ century some of the earliest leadership literature and research studied people who were successful leaders already(Turner and Baker, 2018). Many scholars have argued that leaders were a result of societies they lived in.

As trait-based leadership theories are considered by some scholars and researchers as an obsolete leadership style and theory.

\section{Behaviour leadership theories}

Behaviour leadership theory is the opposite of trait-based leadership theories as it focuses on the leader's behaviour and action rather than trait and leadership skills (Turner and Baker, 2018), behaviour leadership theory believes that " great leaders are made not born". Behaviour leadership was the natural evolvement of the great man theory as it identifies certain behaviours that determines and identifies leaders (Hernandez et al., 2011).

\section{Situational/contingency leadership theories}

As researchers and scholars moved away from trait and behaviour-based leadership theories the quest of leadership theory search started. Scholars identified a new theory at that time which matches leaders' behaviours with their follower's capacity of handling different roles and achieving designated goals set by the leader in different situations(Hernandez et al., 2011). The main driver of this theory at that time was the motivation of employees and followers by looking at the leader's management style and the environment he/she is operating in (Fiedler, 1976). 


\section{Leader/ follower model}

This leadership style or theory focuses on the response of leaders to followers' capabilities and abilities to adapt to changes and perform efficiently (Fiedler, 1976). The attention to the level of interaction between leaders and followers and the level of follower's maturity in term of the understanding challenges facing the organization and the need for change (Lord, 1977) are important factors of such leadership style.

\subsubsection{Newer leadership theories}

Newer leadership theories are someway charismatic, inspiring in the relationship between leaders/followers and transactional. Avolio (2009) outlined new approaches to leadership which "emphasized symbolic leader behaviour, visionary, inspirational messages, emotional feelings, ideological and moral values, individualized attention, and intellectual stimulation"(Avolio et al., 2009, p. 766). Those new approaches to leadership resulted in new ways of looking at and understanding the concept of leading and being led. New leadership charasmatic and transformational leadership where the centre of interest to scholars and researchers in the past two decades (Avalio, 2009). Newer leadership models are believed to bring followers to "higher levels of inspiration, aptitude, and performance" (Avolio et al., 2009, p. 766).

Newer leadership theories have mainly concentrated in the past two decades on transformational and transactional leadership as the most effective and efficient leadership styles. Those studies and researches have outlined many gaps in leadership which are related to the relationship between followers and leaders', while other studies have highlighted the need of newer leadership style (Turner and Baker, 2018) that looks at the macro management of organizational transformation through most suitable leadership style. The need for an efficient leadership style that interconnects various change agents that are accountable for the proper implementation of those required changes is essential.

\subsubsection{Collective/team leadership theory}

Collective or team leadership theory is an approach to leadership which is leveraged on the human aspects focusing on individual and encouraging their positive participation in decision-making process (Arredondo Trapero \& De Lozada, 2010). Collective 
approaches to leadership are built around the concept of moving from a single leadership to a leadership model where "followers and groups exercise shared leadership to initiate transformative change" (Eberly et at., 2013, p. 427). Collective/team leadership theories are decentralized where leadership can be rotated or shared based on the situation and current challenge facing the organization, operating at multilevel, formal/informal and dynamic in its approach to leadership as leaders are encouraged to be proactive in their leadership (Friedrich et al., 2014).

\subsubsection{Global leadership theories}

Global leadership theories are those newer theories that recognizes the complexity of leadership such as instrumental, process and global leadership theories. Global leadership theory is a new approach based on the idea that leadership can take place globally and across different geographic locations (Steers et al., 2012). Few studies and scholars have looked into this leadership approach as it remains an area which is under researched and with a lot to be learned and discovered (Mendenhall et al., 2013). Many scholars have tried to bridge the gap in global leadership literature by identifying the main theory constructs by approaching leadership as a culture and the expected role of global leader (Steers et al., 2012). Global leadership theories approach leadership from two different prospective local or domestic and global or international (Mendenhall et al., 2012). Global leadership theory is defined as "the process of influencing others to adopt a shared vision through structures and methods that facilitate positive change while fostering individual and collective growth in a context characterized by significant levels complexity, flow and presence" (Mendenhall et al., 2012, p. 500). These researchers look at global leadership as influencing and leading individuals or groups of individuals in multiple regions towards achieving the collective organizational goals. Global leadership is about leading through dissimilar cultures and can be looked at as either cultural or universal (Antonakis and House, 2014).

Newer leadership theories as discussed above are especially transformational leadership. Researchers have focused in their studies in past decades of transformational and transactional leadership as the most effective and efficient leadership style. Those studies and researches have highlighted many gaps in the leadership many of them are related to the relationship between followers and leaders' others were highlighting the need of newer leadership style that look at macro managing the organizational transformation throw the most suitable leadership style. The need for a leadership style 
that interconnects different change agents that are responsible for the implementation of those required changes.

\subsection{Transactional Leadership (vertical)}

Weber (1947) and Burns (1978) described three types of leaders and leadership styles in their theories which are transactional, charasmatic and transformational leaders and leadership will be discussed in this research. In this suction of the review we are going to discuss and describe transactional leadership and how its perceived by different scholars and different schools of thoughts. Transactional leadership has many descriptions all related to the nature of transactional leadership style. Transactional leadership also known as bureaucratic leadership (Max Weber, 1947) due to its nature as transactional leaders operate in structured bureaucratic environment. Managerial leadership is another name for transactional leadership as transactional leaders pay much attention to the supervising role of leaders, group performance, organizational structures, and demands follower's compliance to changes through incentivising their followers to carry out their expected duties by a strict reward/punishment system. This reward/punishment exchange system rewards employees to be efficient in their performance by meeting leaders' goals and targets on the other hand employees how fail to meet leader's expectation and insufficient performance levels get punished by lower merits and cuts in their incentives until improvement to their performance and outcomes are noticed (Dai et al., 2013). The reward/punishment systems are strictly structured based on mutual agreement and understanding between followers and leaders (House and Shamir, 1993). Vertical leadership is another name or description of transactional leadership as transactional leader operates based on authoritarian concept of leadership in a hierarchy where information and communication flows topdown in a vertical flow.

Transactional leadership was looked at as the most efficient and accurate way of manegment and organizational change implementation instrument to ensure organizational goals and targets are met in the upmost appropriate mean in the last two decades (Bass et al., 2003). This leadership style manages organizations in conventional way by defining followers' duties and responsibilities as per their job descriptions and as mentioned above by rewarding them for achieving the agreed-on targets or punishing them in the case of individual inability to achieve those agreed goals (Bass, 1999). Transactional leaders pursue high performance and goal achievement of their followers (Prasad and Junni, 2016; Howell and Hall-Merenda, 1999). One of the main issues that 
TABLE 2: Advantage and disadvantage of transactional leadership.

Advantage
Team member motivation to productivity
maximization
Achievable creation to induvial at different
levels
Clear chain of command and hierarchy
Focused on maximization of productivity and
cost reduction
Simple implementation
Clear punishment/reward system

Advantage

Team member motivation to productivity aximization

Disadvantage
Strict in rules and regulation
Illumination of innovation due to rigidness and
unwieldiness
Doesn't create leaders as much as followers
Focuses on consequences rather than creativity
Doesn't take into factor humanitarian factors
Reward based motivation only limiting
motivation.

makes transactional leader's negative perception in today's world of interorganizational environment is its lack of ability and approach into creativity as they are interested maintain the status quo (Bass, 1985). Such leadership is very effective during emergencies and in environment where strict rules and regulations are essential to carry out individual responsibilities safely and professionally (Dai et al., 2013).

\subsection{Transformational leadership (horizontal)}

The concept of transformational leadership was described by Bass 1978 as a leadership style that focuses on the relationship between leaders and followers. In his work transformational leadership was studied as a political leadership potential for political parties and government sector. The transformational leadership theory was expanded later to a broader area of implementation and applicability in organisational leadership (Bass and Avolio, 1994). Scholars and researchers have shown great interest in studying the connection between organizational transformation and its influence on organizational performance during organisational transformation (Judge and Piccolo, 2004). Unlike transactional leadership theory, transformational leaders don't depend on the rewards exchange system. Transformational leaders depend on the understanding of their followers needs. Transformational leaders lead by example as they position themselves as role models for their followers in order to achieve mutual trust and gain their confidence. Transformational leaders seek to motivate followers by understanding their needs, requirement and align their personal interest, values to the collective organizational interest (Bass et al., 2003). Leaders are able to influence and convince their followers by stressing the importance of change to the organizational growth and future vision of the company which leads to prosperity and personal employees benefit (Hamdsta et al., 2014). Followers are encouraged by leaders to look at organizational as an opportunity 
for followers to learn and be more competent (Hetland et al., 20111). Followers are treated as independent individuals (Bass 1985), and are aware of the importance of improving their capabilities, raising their competencies, and skills (Melvyn Hamstra et al., 2014). Transformational leaders are those who inspire followers to perform outstandingly and achieve optimal results (Robbins and Coulter, 2007). Warrilow (2012) has identified that charisma, influence, inspirational motivation, intellectual stimulation, and attention are the six transformational styles.

TABLE 3: Advantages and disadvantages of transformational leadership.

\begin{tabular}{ll|l}
\hline 1 & $\begin{array}{l}\text { Advantage } \\
\text { Retain employees }\end{array}$ & $\begin{array}{l}\text { Disadvantage } \\
\text { Can develop negative outcomes. }\end{array}$ \\
2 & $\begin{array}{l}\text { Higher productivity by satisfying followers } \\
\text { demands }\end{array}$ & $\begin{array}{l}\text { Depends on continuous communication } \\
\text { which might be unachievable sometimes. }\end{array}$ \\
\hline 3 & $\begin{array}{l}\text { Influences others to adopt to organisational } \\
\text { changes }\end{array}$ & $\begin{array}{l}\text { Get Constant feedback to maintain the } \\
\text { enthusiasm within the group or team. }\end{array}$ \\
\hline 4 & $\begin{array}{l}\text { Transformative in their vision } \\
\text { Focuses on induvial needs instead of the }\end{array}$ \\
\hline 6 & Creates enthusiasm in work environment & Aroup or team \\
\hline 6 & Excellent communicators and listeners & Ignores protocols \\
\hline
\end{tabular}

Transformational leaders are inspiring, and charasmatic leaders who motivates employees by achieving organizational collective goals (Burns, 1978). This motivational effort inspires followers to share the organizational vision encouraging other induvial. Burns (1978) identified the main four characteristics of transactional leaders. First, they are instrumental in their abilities to attract individual who value their charisma, and are inspired by them. Second, they inspire induvial and motivate them to share their vision taking a participating role in the organizational goal achievement. Third, creativity is encouraged by them to solve issue and challenges with out of the box solutions. Fourth, support individuals by helping them grow and mature in their positions, and role to assume leadership role once they are competent. Scholars agree that transformational leaders achieve impressing outcomes (Anderson et al., 2017).

\section{Discussion}

The subject of organizational change and organizational transformation is of much importance to scholars and practitioners and identified as a process (Beckhard, 2006) where organizations allocate their available resources to ensure the effective execution of the transformational changes as planned. Organization transformation is an essential element of prosperity, continuously, consistency and sustainability (Levene and Braganza, 1996) to organizations and institutions. Organisational change can take 
many forms radical to incremental or continuous depending on the business nature and the organization maturity (Francis, Bessant and Hobday, 2003). As this research is highlighting the importance of having plural leadership to be able to execute and implement those planed organizational changes. Plural leadership in this paper refers to combination of transactional and transformational leadership that could be used as an approach to leadership during organisational transformation. Plural leadership is defined as "collective phenomenon that is distributed or shared among different people, potentially fluid and constructed in interaction (Dennis et al., 2012, p. 212). The means of the efficient execution of organizational transformation and change is through leadership. Having the right leadership can ensure the implementation of organizations in their transformation initiatives (Higgs and Rowland, 2011). As this research is discussing the best practice in leadership raises the concept of plural leadership styles mainly talking about combination of leadership styles. Many scholars do describe transactional leadership which was traced back to Max Weber 1947 as traditional leadership. Transactional leadership is called organizational, managerial or conventional leadership as it focuses on the vertical authoritarian relationship and power-driven leadership (Avolio \& Bass, 1997). Transactional or vertical leadership is a very effective leadership style and instrument during crises, emergency situations and projects that are needed to be carried out in a specific fashion (Dai et al., 2013). This specific vertical leadership style is conventional but effective (Bass, 1999) and depends on establishing clear goals and setting the right reward/punishment system. This approach to leadership is adopted by many organisations and institutions that take displin and punctuality as an important aspect of thie organizational behaviour.

On the other hand, transformational leadership is about employees and individual relationships (Burns 1978) represent the other part of this research which is basically manging teams and departments in a more horizontally and less authoritarian manner. Many scholars and researchers link transformational leadership to effective managerial performance and results during organizational transformation (Bass \& Riggio, 2006). In transformational leadership leaders have better understanding of individual requirement and understands the necessity of changes to their organization, employees are encouraged and inspired by their leaders to execute the institutionalizing change (Bass, 1997). Since transformational leaders urge and direct followers to look at things from a different perspective to achieve exceptional results (Robbins and Coulter, 2007). Transformation leaders are inspiring and influencing leaders who motivate, inspire and influence individual to achieve the overall organizational goals (Bass and Avolio, 1994) which is also achievable by aligning employees interests with the collective 
organizational interests (Kuhnert, 1994; Andereson et al., 2017). Having transactional leadership as an approach to leading and manging organisations alone isn't enough. Transactional (vertical) leadership is a directive leadership style that is needed during in crises manegment and hazarders environment where strict rules and regulations are in place (Binci, Cerruti and Braganza, 2016).

As discussed above in the literature review plural leadership during organizational transformation where there is an authoritarian leadership that is conventional and depends on position, power and authority (Max Weber, 1947) and inspire influential leadership that is belt around the employee's satisfaction (Burns, 1978) and alignment of induvial interest with organizational collective interest is needed (Kuhnert, 1994; Anderson et al., 2017). Having those two contradicting and complementing leadership styles really insures that organizational changes are executed as changes are communicated and channelled vertically from top to bottom with specified goals and targets (Dai et al., 2013) and horizontally cross the board of the organization as well as channelling communication from bottom to top, right to left, left to right (Bass and Avolio, 1990). This literature review has highlighted the importance and need transformational alongside transactional leadership on achieving enhanced performance and quality of relationship between induvial, middle manegment, top manegment during organizational change process and ensuring the flow of communication top-bottom, bottom-top (Pawar \& Eastman, 1997).

Organisation changes are requirements off stakeholders represented by board of Directors or steering committees appointed by those stakeholders to implement changes. The implementation of organizational changes is either structural changes or operational changes that requires the right leadership approach and style. The importance of leaders' role is significant. A proper execution and implementation of planned changes. This research is conducted to explore the importance of having different leadership approaches to different levels within the structure and the hierarchy of the organisation.

\section{Conclusion}

The paper focused on the impact of implementing horizontal leadership to boost and kickstart positive and efficient performance and result with vertical leadership during organizational transformation. Having transformational leaders' engagement in changes implementation during organizational transformation had a very positive impact and strong enhancement to performance level. It's very clear from the literature reviewed 
and discussion that vertical leadership is still seen as the main initiator of changes but having horizontal leadership makes sure that those changes are flowing smoothly within the organization's boundaries and vertically from top-bottom and bottom-top. More effective implementation of changes is achievable due to the efficient communication though different layers of the organization and ensure that all parts and components of the organization shares the same collective interest and realizes the need for change in other words changes are riming in harmony through the organization department to department and division to division. At the end its noticed that there isn't a most efficient leadership as efficiency is circumstantial and can be changing as situations and challenges change due the life course of the organisation. Whoever a shortage in the interaction between leader theories and social network leadership theories was identified as a gap and an area to be researched and studied for future research.

\section{References}

[1] Transformational and charismatic leadership: the road ahead. (2013) Emerald.

[2] 'Advances in interdisciplinary studies of work teams', Advances in interdisciplinary studies of work teams, .

[3] 'Human resource management review', Human resource management review, .

[4] 'Leadership \& organization development journal', Leadership \& organization development journal, .

[5] Tourism Management Perspectives. Available at: (Accessed:.Transactional Leadership.

[6] Transformational and Charismatic Leadership The Road Ahead 10th Anniversary Edition.

[7] Anderson, H.J., Baur, J.E., Griffith, J.A. and Buckley, M.R. (2017) 'What works for you may not work for (Gen)Me: Limitations of present leadership theories for the new generation', The Leadership Quarterly, 28(1), pp. 245-260. doi: 10.1016/j.leaqua.2016.08.001.

[8] ANNE NEDERVEEN PIETERSE, DAAN VAN KNIPPENBERG, MICHAÉLA SCHIPPERS and DAAN STAM (2010a) 'Transformational and transactional leadership and innovative behavior: The moderating role of psychological empowerment', Journal of Organizational Behavior, 31(4), pp. 609-623. doi: 10.1002/job.650.

[9] Antonakis, J. and House, R.J. (2014b) 'Instrumental leadership: Measurement and extension of transformational-transactional leadership theory', The Leadership Quarterly, 25(4), pp. 746-771. doi: 10.1016/j.leaqua.2014.04.005. 
[10] Baker-Shelley, A., van Zeijl-Rozema, A. and Martens, P. (2017) 'A conceptual synthesis of organisational transformation: How to diagnose, and navigate, pathways for sustainability at universities?', Journal of Cleaner Production, 145, pp. 262-276. doi: 10.1016/j.jclepro.2017.01.026.

[11] Bass, B.M. (1998b) Transformational leadership. Mahwah, NJ [u.a.]: Erlbaum.

[12] Binci, D., Cerruti, C. and Braganza, A. (2016b) 'Do vertical and shared leadership need each other in change management?', Leadership \& Organization Development Journal, 37(5), pp. 558-578. doi: 10.1108/LODJ-08-2014-0166.

[13] Blaudziunas, R. (2016) 'Information about article authors', Engineering Economics, 27(2). doi: 10.5755/j01.ee.27.2.14867.

[14] Bush, T. (2018) 'Prescribing distributed leadership', Educational Management Administration \& Leadership, 46(4), pp. 535-537. doi: 10.1177/1741143218768403.

[15] D'Innocenzo, L., Mathieu, J.E. and Kukenberger, M.R. (2016) 'A Meta-Analysis of Different Forms of Shared Leadership-Team Performance Relations', Journal of Management, 42(7), pp. 1964-1991. doi: 10.1177/0149206314525205.

[16] Dai, Y., Dai, Y., Chen, K. and Wu, H. (2013a) 'Transformational vs transactional leadership: which is better?', International Journal of Contemporary Hospitality Management, 25(5), pp. 760-778. doi: 10.1108/IJCHM-Dec-2011-0223.

[17] Dai, Y., Dai, Y., Chen, K. and Wu, H. (2013b) 'Transformational vs transactional leadership: which is better?', International Journal of Contemporary Hospitality Management, 25(5), pp. 760-778. doi: 10.1108/IJCHM-Dec-2011-0223.

[18] Dai, Y., Dai, Y., Chen, K. and Wu, H. (2013c) 'Transformational vs transactional leadership: which is better?', International Journal of Contemporary Hospitality Management, 25(5), pp. 760-778. doi: 10.1108/IJCHM-Dec-2011-0223.

[19] Epitropaki, O. and Martin, R. (2013a) 'Transformational-transactional leadership and upward influence: The role of Relative Leader-Member Exchanges (RLMX) and Perceived Organizational Support (POS)', The Leadership Quarterly, 24(2), pp. 299315. doi: 10.1016/j.leaqua.2012.11.007.

[20] Epitropaki, O. and Martin, R. (2013b) 'Transformational-transactional leadership and upward influence: The role of Relative Leader-Member Exchanges (RLMX) and Perceived Organizational Support (POS)', The Leadership Quarterly, 24(2), pp. 299315. doi: 10.1016/j.leaqua.2012.11.007.

[21] Francis, D., Bessant, J. and Hobday, M. (2003) 'Managing radical organisational transformation', Management Decision, 41(1), pp. 18-31. doi: 10.1108/00251740310462023.

[22] Heyden, M.L.M., Fourné, S.P.L., Koene, B.A.S., Werkman, R. and Ansari, S.S. (2017) 'Rethinking 'Top-Down' and 'Bottom-Up' Roles of Top and Middle Managers in 
Organizational Change: Implications for Employee Support', Journal of Management Studies, 54(7), pp. 961-985. doi: 10.1111/joms.12258.

[23] Hovik, S. and Hanssen, G.S. (2015) 'The Impact of Network Management and Complexity on Multi-Level Coordination', Public Administration, 93(2), pp. 506-523.

[24] HOVIK, S. and HANSSEN, G.S. (2015) 'THE IMPACT OF NETWORK MANAGEMENT AND COMPLEXITY ON MULTI-LEVEL COORDINATION', Public Administration, 93(2), pp. 506-523. doi: 10.1111/padm.12135.

[25] Lee, S.D., Weiner, B.J., Harrison, M.I. and Belden, C.M. (2013) 'Organizational Transformation', Medical Care Research and Review, 70(2), pp. 115-142. doi: $10.1177 / 1077558712458539$.

[26] Levene, R. and Braganza, A. (1996) 'Controlling the work scope in organisational transformation: a programme management approach', International Journal of Project Management, 14(6), pp. 331-339. doi: 10.1016/0263-7863(96)00048-8.

[27] Ma, X. and Jiang, W. (2018b) 'Transformational Leadership, Transactional Leadership, and Employee Creativity in Entrepreneurial Firms', The Journal of Applied Behavioral Science, 54(3), pp. 302-324. doi: 10.1177/0021886318764346.

[28] Melvyn R. W. Hamstra, Nico W. Van Yperen, Barbara Wisse and Kai Sassenberg (2014b) 'Transformational and Transactional Leadership and Followers' Achievement Goals', Journal of Business and Psychology, 29(3), pp. 413-425. doi: 10.1007/s10869013-9322-9.

[29] Stebbings, H. and Braganza, A. (2008a) Exploring continuous organisational transformation as a form of network interdependence. British Academy of Management,.

[30] Turner, J.R. and Baker, R. (2018) 'A review of leadership theories: identifying a lack of growth in the HRD leadership domain', European Journal of Training and Development, 42(7/8), pp. 470-498. doi: 10.1108/EJTD-06-2018-0054.

[31] Tyssen, A.K., Wald, A. and Spieth, P. (2014a) 'The challenge of transactional and transformational leadership in projects', International Journal of Project Management, 32(3), pp. 365-375. doi: 10.1016/j.jproman.2013.05.010.

[32] Tyssen, A.K., Wald, A. and Spieth, P. (2014b) 'The challenge of transactional and transformational leadership in projects', International Journal of Project Management, 32(3), pp. 365-375. doi: 10.1016/j.jproman.2013.05.010.

[33] Xenikou, A. (2017a) 'Transformational Leadership, Transactional Contingent Reward, and Organizational Identification: The Mediating Effect of Perceived Innovation and Goal Culture Orientations', Frontiers in psychology, 8, pp. 1754. doi: 10.3389/fpsyg.2017.01754. 
[34] Xenikou, A. (2017b) 'Transformational Leadership, Transactional Contingent Reward, and Organizational Identification: The Mediating Effect of Perceived Innovation and Goal Culture Orientations', Frontiers in psychology, 8, pp. 1754. doi: 10.3389/fpsyg.2017.01754.

[35] Yahaya, R. and Ebrahim, F. (2016) 'Leadership styles and organizational commitment: literature review', Journal of Management Development, 35(2), pp. 190-216. doi: 10.1108/JMD-01-2015-0004. 